\title{
Effects of Random Fibre Reinforcement on the Density of Granular Materials
}

\author{
O. Ajayi, L. Le Pen, A. Zervos \& W. Powrie \\ Faculty of Engineering and the Environment, University of Southampton, Southampton SO17 1BJ, United \\ Kingdom
}

\begin{abstract}
The growing need for the development of resilient track materials (including ballast) to cope with increasing train speed, load and frequency has led to a focus on optimizing performance and minimizing maintenance requirements. The use of fibres of random orientation has been shown to improve significantly the mechanical properties of sand. It is reasonable to expect that such random reinforcement will have similar effects on ballast, provided that a thorough understanding of the reinforcement mechanisms at both the micro and macro-scale is reached. This paper presents data based on macro-observations of fibre reinforced scaled ballast that suggest that fibres influence the micro-mechanical interactions governing the volume change of the mixture rather than influencing shear strength mobilization which is enhanced by the tensile capacity of the fibres in the mixture. In addition, the potential benefits of the proposed reinforcement technique in railway ballast are illustrated and discussed.
\end{abstract}

\section{INTRODUCTION}

It is well established that the degree of particle packing significantly influences the strength and deformation behaviour of soils and crushed rocks. In terms of railway track stability, there is also a consensus that the strength and stability of ballast is enhanced by increased density (e.g. Selig and Waters, 1994; Indraratna et al., 1998). Ballast is one of the primary components of a railway track and is the focus of the majority of track maintenance and renewal. The growing demands placed on railways, have given rise to a need to develop cost effective ways of improving the performance and reducing maintenance requirements of railway ballast. The addition of random oriented fibres in ballast is one possible way of increasing the life span of railway track. However, the effects of the addition of fibres on the ballast structure and performance are unknown.

Evidence of how the addition of randomly oriented fibres affects the packing of a granular medium has been reported by Diambra et al., (2010). They showed that the addition of fibres to sand produces a gradual reduction in the maximum dry density of the mixture. However, the effect of fibres on the packing structure has not been examined rationally particularly with regard to the characteristics (e.g. void ratio, dry density, fibre content) of the mixture. Also, the effect of the addition of fibres in relatively large sized granular materials (e.g. scaled ballast) is unknown. Diambra et al. (2013) stated that the lack of understanding of the interaction mechanism between granular materials and fibres is one of the lim- iting factors on the use of fibre reinforcements on an industrial scale.

The effect of randomly oriented fibres on the packing structure of scaled ballast is investigated in this paper. The focus of the laboratory tests was on assessing how the maximum and minimum void ratios of a fibre reinforced granular material vary with fibre content. To provide further understanding of the effects of fibre reinforcement on granular materials (scaled ballast), a description of the effects of the addition of fibres to granular materials and a discussion of the physical implications for the mechanical behaviour of the mixture as measured in triaxial tests are presented.

\section{LABORATORY TESTS}

\subsection{Materials}

Test reported in this paper were carried out on a parallel-graded material (granite) with $1 / 3$ the size of a typical Network Rail ballast gradation (Figure 1). The use of scaled ballast offers an attractive and economical means of developing an understanding of the mechanics of full size ballast $\left(\mathrm{D}_{100}=62 \mathrm{~mm}\right)$. Le Pen et al. (2013) demonstrated that although measurable variations in form and roundness occur with particle size over a range of sieve intervals, these differences are slight and do not militate against the use of scaled material in investigating the factors influencing macro-mechanical behaviour. 
Tape-like polyethylene fibres were used with the dimensions and typical mechanical properties summarised in Table 1.

\subsection{Specimen Preparation}

The scaled ballast-fibre mixture was prepared by hand-mixing known masses of fibre and scaled ballast (SB) in a plastic container. The resulting mixture appeared to be reasonably random and homogeneous.

\subsubsection{Dry density tests}

The maximum dry density of the scaled ballastfibre mixture was determined by compaction in three layers into a cylindrical mould $150 \mathrm{~mm}$ diameter and $246 \mathrm{~mm}$ in height. Preliminary tests showed that twenty blows from a standard Proctor rammer produced a density similar to that obtained using the vibration method of compaction. To prevent particle breakage due to the impact of the rammer, a circular shaped laminated piece of wood padded with rubber was placed on top of each layer during compaction.

As there are no widely established methods of determining the minimum density of large sized granular materials, a technique of carefully placing scaled ballast in the cylindrical mould, such that the particles would not densify was adopted for the scaled ballast.

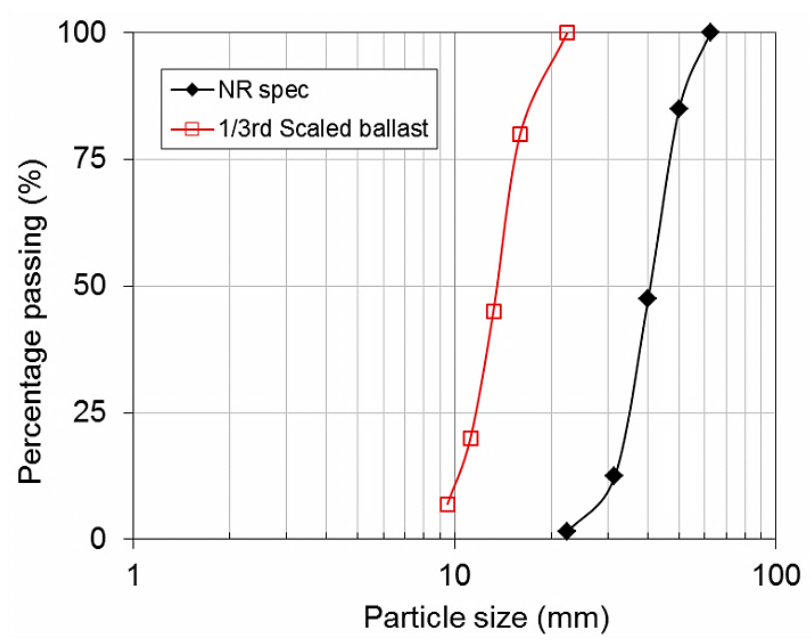

Figure 1. Particle size distribution of $1 / 3$ scaled ballast and Network Rail ballast gradation
Table 1. Typical values of the basic properties of polyethylene fibres

\begin{tabular}{lc}
\hline & Polyethylene \\
\hline Fibre length & $100 \mathrm{~mm}$ \\
Fibre width & $35 \mathrm{~mm}$ \\
Fibre thickness & $0.5 \mathrm{~mm}$ \\
Specific gravity & 0.92 \\
Tensile strength & $\sim 12 \mathrm{MPa}$ \\
Softening temperature & $85^{\circ} \mathrm{C}$ \\
Moisture absorption & $<0.1 \%$ \\
\hline
\end{tabular}

\subsection{Triaxial tests}

Conventional monotonic triaxial tests on specimens $150 \mathrm{~mm}$ in diameter and $300 \mathrm{~mm}$ in height were carried out on fibre reinforced and unreinforced scaled ballast specimens. The fibre-reinforced scaled ballast (FRSB) mixture was prepared in the same way as for the density tests, and the reinforced specimen was then prepared to achieve the densest state corresponding to the minimum void ratio at a given fibre content. The triaxial tests were carried out on dry specimens at a confining stress of $30 \mathrm{kPa}$ to replicate the typically low confining stresses within an unloaded ballast bed (e.g. Indraratna et al., 2010; Sevi and Ge, 2012). The triaxial tests and the initial conditions of the specimen are summarised in Table 2.

\subsection{Description of parameters}

There is no universally accepted definition of void ratio for fibre reinforced granular materials. The main area of disagreement is whether the volume of fibres is considered to be part of the volume of solids or voids. Each approach has implications for the calculated void ratio of the mixture.

Table 2. Triaxial tests carried out

\begin{tabular}{ccc}
\hline Specimen & $e_{o}$ & $\begin{array}{c}\text { Fibre content, } \\
V_{f r}(\%)\end{array}$ \\
\hline Loose SB & 0.87 & - \\
Dense SB & 0.76 & - \\
$V_{f r}=3.2 \%$ & 0.93 & 3.2 \\
\hline
\end{tabular}

Diambra et al. (2010) considered the fibres to be part of the solids component of the sand-fibre mixture and defined the void ratio as the volume of voids divided by the volume of grains plus fibres. This definition does not obviously account for the fact that, in a sand-fibre mixture, grain-fibre interaction may lead to an increase in the void and/or non- 
sand volume compared with pure sand, under the same compactive effort. In particular, the approach will perhaps misleadingly give a lower void ratio for reinforced sand than for the same sand without reinforcement, because the volume of solids (defined in this case as fibres plus sand) increases. Michalowski and Cermak (2003) adopted the same approach of considering the volume of fibres to be part of the solid skeleton but did not present any experimental evidence of its effect on the packing of the mixture. Diambra et al. (2013), in developing a constitutive model for fibre reinforced sands, considered the total volume of voids to be divided into two parts 'attached' to either the sand matrix or to the fibres.

To overcome these limitations a three phase system consisting of voids (air), fibres and grains is adopted in this paper (Figure 2), with relations between the phases defined as:

Void ratio $(e)$ : the ratio of the volume of voids $\left(V_{v}\right)$ to the volume of the grains, hereafter termed "solids" $\left(V_{s}\right)$.

$e=\frac{V_{v}}{V_{s}}$

Volumetric fibre ratio $\left(V_{f r}\right)$ : the ratio of the volume of fibres $\left(V_{f}\right)$ to the volume of solids $\left(V_{s}\right)$

$V_{f r}=\frac{V_{f}}{V_{s}}$

These definitions have the advantage of considering fibres independently of the solids and the voids, while taking $V_{\mathrm{s}}$ to be the common denominator for both parameters.

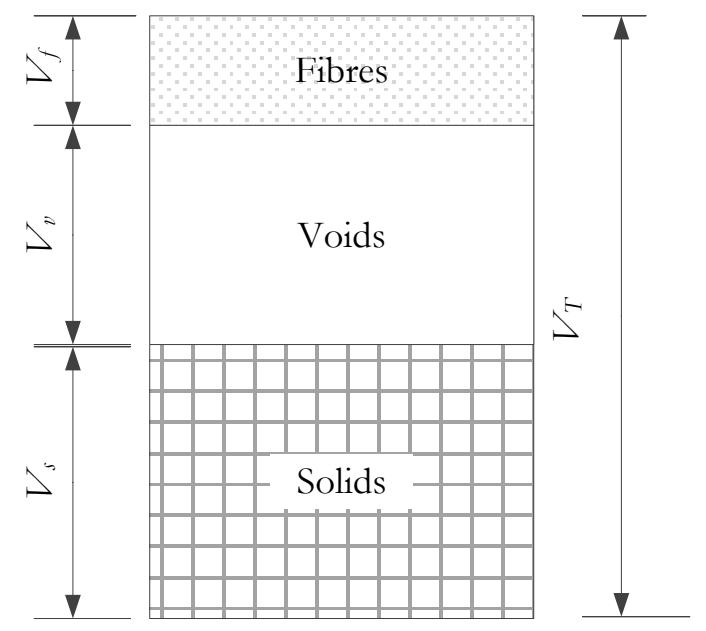

Figure 2. Volumes of phases in a fibre reinforced granular material

\section{RESULTS AND DISCUSSION}

The maximum and minimum void ratios (i.e. $e_{\max }$ and $\left.e_{m i n}\right)$ increases gradually with increasing $V_{f r}$ (Figure 3), indicating that the addition of fibres interferes with the packing of the particles. Ibraim and Fourmont (2007) reported a loss in dry density of the sand-fibre mixture and this was attributed to the greater resistance to compaction provided by the fibres. However, the behaviour of the constituents (i.e. the volumes of fibres, solids and voids) in relation to the observed macro-mechanical behaviour is not fully understood. For example, the data presented in Figure 3 shows that at a given void ratio, a specimen could be relatively loose when $V_{f r}$ is low but relatively dense when $V_{f r}$ is high.

The addition of fibres $V_{f}$ to a granular material will essentially bring about changes in the total volume $V_{T}$ and the volume of voids $V_{v}$ for a given volume of solids $V_{s}$ (Figure 4c); or changes in the volume of solids and the volume of voids (as well as the volume of fibres) within a given constant total volume $V_{T 0}$ (Figure $\left.4 \mathrm{~b}\right)$.

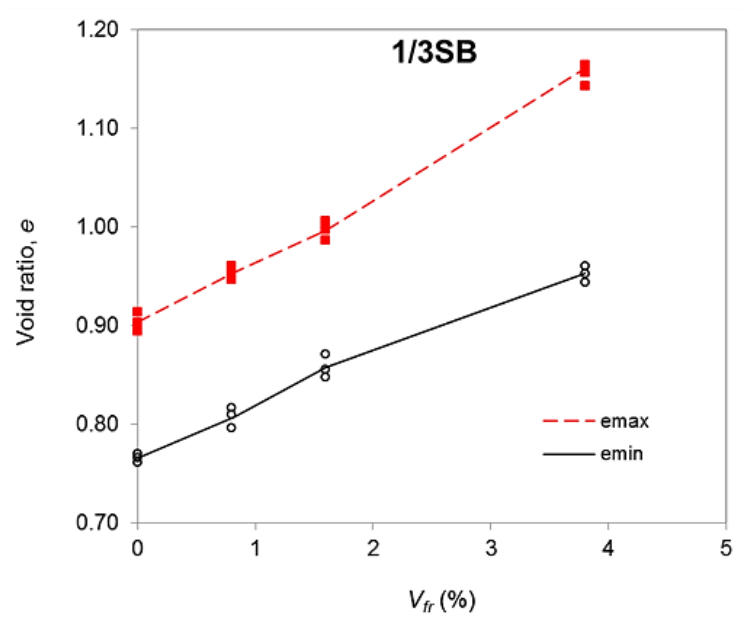

Figure 3. Effect of increasing $V_{f r}$ on the void ratio of reinforced $1 / 3^{\text {rd }}$ scaled ballast while using a constant compactive effort

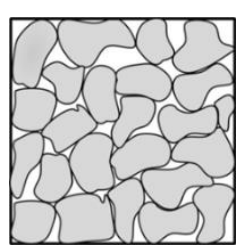

(a)

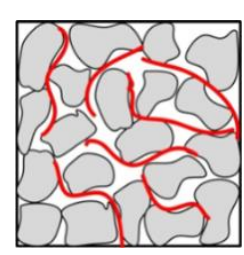

(b)

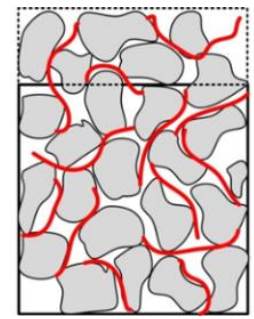

(c)
Figure 4. Effect of adding a volume of fibres, $V_{f}$ (a) Unreinforced granular material i.e. $V_{T 0}, V_{V 0}$ and $V_{S}$; (b) Fibre reinforced granular material at constant $V_{T O},\left(V_{S}+\Delta V_{S}\right)$ and $\left(V_{V O}+\right.$ $\left.\Delta V_{V}\right)$; (c) Fibre reinforced granular material at constant $V_{S},\left(V_{T 0}\right.$ $\left.+\Delta V_{T}\right)$ and $\left(V_{V O}+\Delta V_{V}\right)$ 
Appreciation of the implication of this phenomenon on the mechanical behaviour of fibre reinforced granular materials is important as it will provide the basis for a more robust understanding of the fibre/particle interaction mechanisms.

The effect of fibre reinforcement on the stressstrain behaviour of unreinforced and reinforced scaled ballast is shown in Figure 5. The behaviour of the unreinforced SB samples (Loose and Dense) is typical of granular materials. The reinforced sample $\left(V_{f r}=3.2 \%\right)$ exhibited a higher mobilised strength at large strains. The addition of fibres delays dilation as shown in the volumetric strain plots. This corroborates the findings of Michalowski and Cermak (2003) and Dos Santos et al. (2010). Diambra et al. (2013) however reported an increase in the dilation of specimens reinforced by thread-like fibres. They argued that this is a consequence of an apparent densification of the granular matrix due to the presence of fibres in the voids. This fundamental difference is considered to be a result of the specimen preparation method employed by Diambra et al. (2013), in which a constant volume of specimen and mass of sand was considered while the fibre content was increased. To make the sand-fibre mixture fit into the specimen volume, the compactive effort was increased with increase in fibre content.

To emphasize the effect of fibre reinforcements on dilation, the compression parts (i.e. when $\delta<0$ ) of the plots of the rate of dilation (as defined in Equation 3) against stress ratio, $q / p^{\prime}$ have been removed and a line of the form $q / p^{\prime}=\alpha \delta+M$ (where $\alpha$ is the rate of increase of stress ratio with rate of dilation, and $M$ is the stress ratio when $\delta=0$ ) fitted through the data points (Figure 6). At a given rate of dilation, the reinforced sample shows a greater increase in mobilised strength as demonstrated by the higher $\alpha$ values. The plot of the angle of dilation, $\psi$ against shear strain shown in Figure 7 confirms the effect of fibre reinforcements in inhibiting dilation. It also shows that the maximum rates of dilation exhibited by the reinforced and Loose SB samples were similar owing to their higher $e_{o}$ than the specimen of dense scaled ballast.

$\delta=\frac{\delta \varepsilon_{v o l}}{\delta \varepsilon_{q}}$

where $\delta \varepsilon_{v o l}$ is the plastic volumetric strain increment and $\delta \varepsilon_{q}$ is the plastic triaxial shear strain.
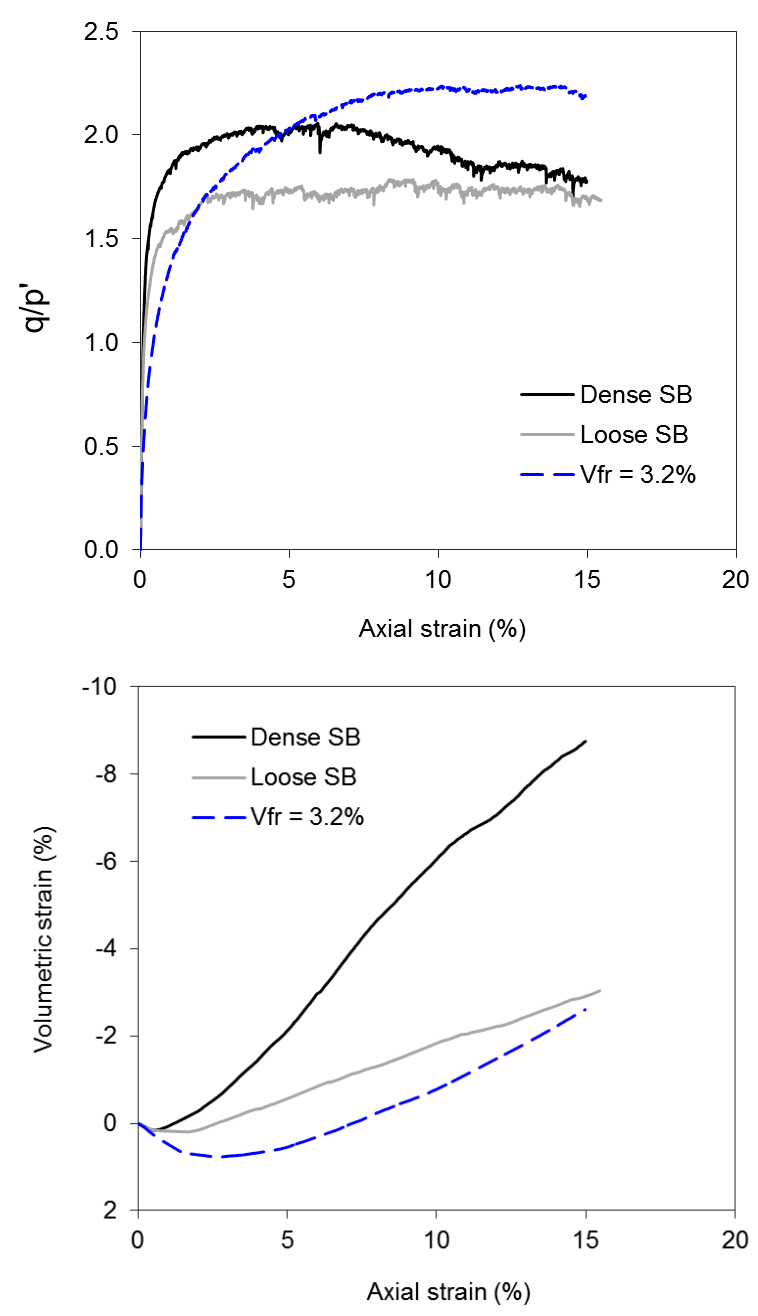

Figure 5. Effects of fibre reinforcements on the development of stress ratio, $q / p^{\prime}$ and volumetric strain with axial strain for scaled ballast

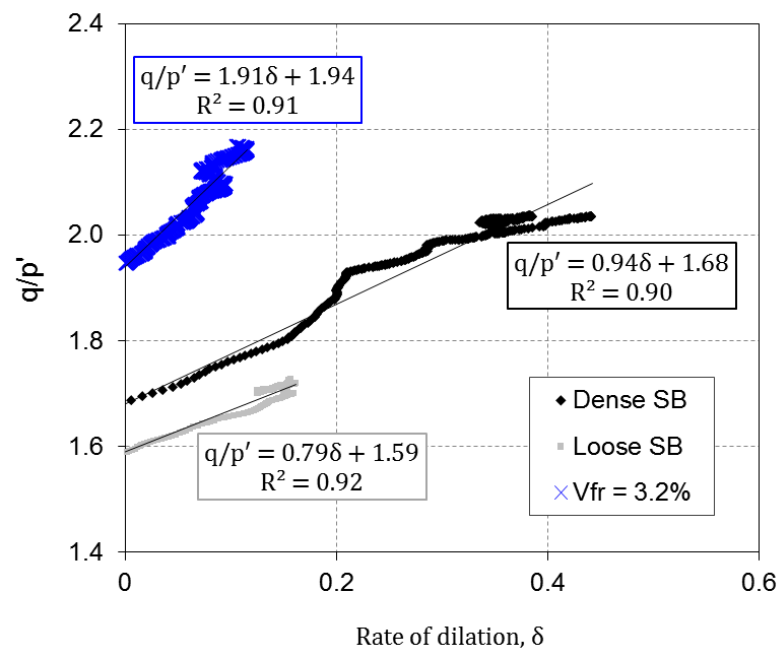

Figure 6. Effects of fibre reinforcements on the rate of dilation, $\delta$ SB specimens when $\delta \geq 0$ 


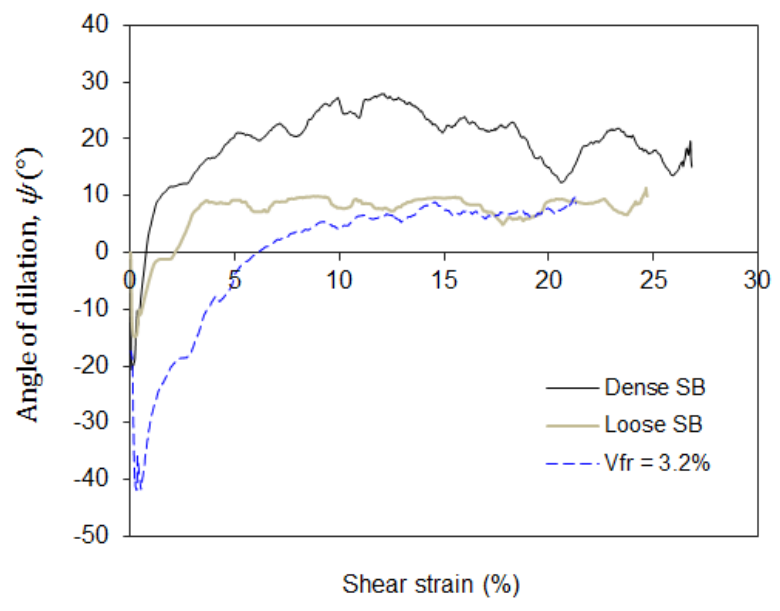

Figure 7. Effect of fibre reinforcement on the variation of angle of dilation, $\psi$, with shear strain

The addition of fibres to a granular material prevents the grains from packing and thus creates both macro voids (due to the packing of a smaller number of solids within a given total volume) and micro voids (arising from the inability of fibres to form perfect bonds with particles). During shear, it can be argued that the voids (macro and micro) created influence the micro-mechanical interactions governing volume change of the specimen (e.g. sliding, rolling, coordination number and local voids), while the shear strength mobilisation is enhanced by the tensile capacity of the fibres in the mixture.

The use of fibres in granular materials thus leads to reduced lateral spread (minor principal strain) of the mixture, and the mobilization of higher stress ratios. This is potentially beneficial to the proposed use in railway ballast, and is similar to the improvement offered by geogrids in railway ballast by the reduction in permanent vertical settlement and lateral spread (e.g. McDowell et al., 2006; Indraratna et al., 2010; Chen et al., 2012). The latter is believed to be due to the restriction provided by geogrids to the lateral movement of ballast particles.

\section{CONCLUSION}

The relationship between the structural packing and mechanical behaviour of a fibre reinforced scaled ballast has been investigated through macroobservations of modified density and triaxial compression tests. Triaxial tests on a fibre reinforced specimen revealed that the shear strength mobilized for a given rate of dilation is greater than for unreinforced specimens. It is suggested that the micromechanical interactions governing volume change in a reinforced specimen are influenced by the disturbance resulting from the presence of the fibre reinforcements, while shear strength mobilization is enhanced by the tensile resistance of fibres.
This work provides a basis for understanding fibre/particle interaction mechanisms at a macro-scale with the intention of up scaling to full-size ballast. Likely benefits include a more ductile material behaviour and a reduction in lateral spread.

\section{ACKNOWLEDGEMENTS}

This research was supported by the UK Engineering and Physical Sciences Research Council (EPSRC) through the TRACK21 Programme Grant (EP/H044949). The first author further acknowledges the support of the University of Southampton.

\section{REFERENCES}

Chen, C., Mcdowell, G.R. \& Thom, N.H. (2012). Discrete Element Modelling of Cyclic Loads of Geogrid-Reinforced Ballast under Confined and Unconfined Conditions. Geotextiles and Geomembranes, 35 (0) 76-86.

Diambra, A., Ibraim, E., Russell, A.R. \& Wood, D.M. (2013). Fibre Reinforced Sands: From Experiments to Modelling and Beyond. International Journal for Numerical and Analytical Methods in Geomechanics, 37 (15) 2427-2455.

Diambra, A., Ibraim, E., Wood, D.M. \& Russell, A.R. (2010). Fibre Reinforced Sands: Experiments and Modelling. Geotextiles and Geomembranes, 28 (3) 238-250.

Dos Santos, A.P.S., Consoli, N.C. \& Baudet, B.A. (2010). The Mechanics of Fibre-Reinforced Sand. Geotechnique, 60 (10) 791-799.

Ibraim, E. \& Fourmont, S. Year. Behaviour of Sand Reinforced with Fibres. In: LING, H. I., CALLISTO, L., LESHCHINSKY, D. \& KOSEKI, J., eds. Soil Stress-Stain Behavior: Measurement, Modeling and Analysis, 2007. 807-818.

Indraratna, B., Ionescu, D. \& Christie, H.D. (1998). Shear Behavior of Railway Ballast Based on Large-Scale Triaxial Tests. Journal of Geotechnical and Geoenvironmental Engineering, 124 (5) 439-449.

Indraratna, B., Nimbalkar, S., Christie, D., Rujikiatkamjorn, C. $\&$ Vinod, J. (2010). Field Assessment of the Performance of a Ballasted Rail Track with and without Geosynthetics. Journal of Geotechnical and Geoenvironmental Engineering, 136 (7) 907-917.

Mcdowell, G.R., Harireche, O., Konietzky, H., Brown, S.F. \& Thom, N.H. (2006). Discrete Element Modelling of Geogrid-Reinforced Aggregates. Proceedings of the Institution of Civil Engineers-Geotechnical Engineering, 159 (1) 35-48.

Michalowski, R.L. \& Cermak, J. (2003). Triaxial Compression of Sand Reinforced with Fibers. Journal of Geotechnical and Geoenvironmental Engineering, 129 (2) 125-136.

Pen, L.M., Powrie, W., Zervos, A., Ahmed, S. \& Aingaran, S. (2013). Dependence of Shape on Particle Size for a Crushed Rock Railway Ballast. Granular Matter, 1-13.

Selig, E.T. \& Waters, J.M. (1994). Track Geotechnology and Substructure Management, T. Telford.

Sevi, A. \& Ge, L. (2012). Cyclic Behaviors of Railroad Ballast within the Parallel Gradation Scaling Framework. Journal of Materials in Civil Engineering, 24 (7) 797-804. 